\title{
THE CONCEPT OF ESSENTIAL CLIMATE VARIABLES IN SUPPORT OF CLIMATE RESEARCH, APPLICATIONS, AND POLICY
}

\author{
by Stephan Bojinski, Michel Verstraete, Thomas C. Peterson,
} Carolin Richter, Adrian Simmons, and Michael Zemp

Described is the concept of Essential Climate Variables developed under the Global Climate Observing System for a range of applications, as well as to provide an empirical basis for understanding past, current, and possible future climate variability and change.

0 bservations are fundamental to advancing scientific understanding of climate (Doherty et al. 2009; Shapiro et al. 2010) and delivering the vetted, timely, and purposeful climate information needed to support decision making in many sectors. Observations and monitoring are key elements of the emerging Global Framework for Climate Services (WMO 2011a) and more generally support climate research, the assessment of climate change, and the development of policy responses (Fig. 1). For these purposes, observational datasets in general need to be traceable to quality standards, be readily interpretable and freely available, and cover sufficiently long periods: for example, the 30 years traditionally used for calculating climate normals (WMO 2011b). Transparency in the generation of climate datasets is

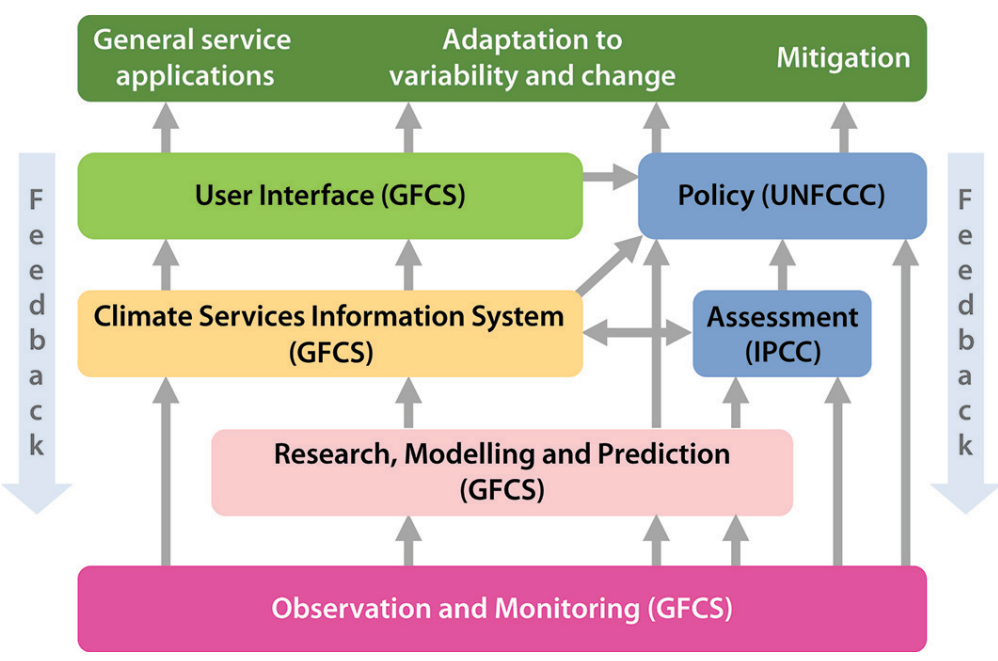

FIG. I. The role of observation within the Global Framework for Climate Services (GFCS) and in support of research; the assessment of climate change, in particular as undertaken by the IPCC; and the development and implementation of policy responses, in particular under the UNFCCC. Gray arrows denote the main directions of flow of climate data and derived information. Feedback for system improvement flows mainly in the opposite direction. The GFCS includes a substantial capacity-development component that underlies all illustrated components. Adapted from WMO (2009, 201 la). 
essential for ensuring the credibility of the climate record (UN 2012).

In the 1990s, gaps in knowledge of climate and declining core observational networks in many countries (Houghton et al. 2012) led to calls for systematic observation of a limited set of critical variables. To provide guidance, the Global Climate Observing System (GCOS) program developed the concept of "essential climate variables" (ECVs), which has since been broadly adopted in science and policy circles.

In this article, we define the ECV concept and describe its provenance, scientific rationale and uptake. We also discuss challenges and opportunities concerning the ECV concept and its possible evolution, in particular with regard to the GCOS-led process of assessment, adequacy, and implementation of global observing systems for climate.

WHAT ARE THE ECVS? An ECV is a physical, chemical, or biological variable or a group of linked variables that critically contributes to the characterization of Earth's climate. ECV datasets provide the empirical evidence needed to understand and predict the evolution of climate, to guide mitigation and adaptation measures, to assess risks and enable attribution of climatic events to underlying causes, and to underpin climate services. The current list of ECVs is specified in GCOS (2010a) (all GCOS reports are available at www.wmo.int/pages/prog/gcos/index .php? name=Publications) and reproduced in Table 1.

More than variables: The ECV concept. The ECVs must not be understood as a select group of stand-alone

AFFILIATIONS: BOJINSKI-World Meteorological Organization, Geneva, Switzerland; VerSTRAETE*_European Commission Joint Research Centre, Ispra, Italy; PETERSON-NOAA/National Climatic Data Center, Asheville, North Carolina; RICHTER-Global Climate Observing System Secretariat, World Meteorological Organization, Geneva, Switzerland; SIMMONS-European Centre for Medium-Range Weather Forecasts, Reading, United Kingdom; ZеMP-University of Zurich, Zurich, Switzerland

*CURRENT AFFILIATION: South African National Space

Agency, Pretoria, South Africa

CORRESPONDING AUTHOR: Stephan Bojinski, World

Meteorological Organization, 7bis Avenue de la Paix, CP 2300 ,

I2II Geneva 2, Switzerland

E-mail: sbojinski@wmo.int

The abstract for this article can be found in this issue, following the table of contents.

DOI:10.1175/BAMS-D-13-00047.1

In final form 13 January 2014

C2014 American Meteorological Society variables; they are part of a wider concept (Fig. 2). ECVs are identified based on the following criteria:

- Relevance: The variable is critical for characterizing the climate system and its changes.

- Feasibility: Observing or deriving the variable on a global scale is technically feasible using proven, scientifically understood methods.

- Cost effectiveness: Generating and archiving data on the variable is affordable, mainly relying on coordinated observing systems using proven technology, taking advantage where possible of historical datasets.

To make practical use of the ECVs, guidance and best practices are needed to enable and support the generation of high-quality, traceable ECV data records (see details in Fig. 2). The ECV concept accommodates mixed or changing observing system technologies and is therefore conducive to meeting user needs for information over the long term. It helps distil a complex field into a manageable list of priorities and related actions (GCOS 2010a).

PROVENANCE. Some 20 years ago, the international community began exploring a more coordinated approach to observing climate on a global scale. The GCOS program, founded in 1992 by the World Meteorological Organization (WMO), the Intergovernmental Oceanographic Commission of the United Nations Educational, Scientific and Cultural Organisation (IOC/UNESCO), the United Nations Environment Programme (UNEP), and the International Council for Science (ICSU), was mandated to define objectives and recommend coordinated action for a global observing system for climate, building on and enhancing existing systems (GCOS 1995; Houghton et al. 2012). The initial plan called for a system based on (i) fundamental scientific priorities and (ii) prioritized observational requirements, informed by scientific and technical progress and evolving user needs. It identified "principal observations" to be addressed by a set of space missions, noting earlier work in support of short-term climate predictions (NRC 1994).

Priorities were further elaborated by exploring which physical variables or combination of variables would be most suitable for long-term climate monitoring (Karl 1996, and references therein; Trenberth 1995). Observational priorities were formulated recognizing the capabilities of current or expected observing systems. 
TABLE I. The essential climate variables (for qualifying details, see GCOS $2010 \mathrm{a}$ ).

\begin{tabular}{|c|c|c|}
\hline \multirow{3}{*}{ Atmospheric } & Surface: ${ }^{a}$ & $\begin{array}{l}\text { Air temperature, wind speed and direction, water vapor, pressure, precipitation, } \\
\text { surface radiation budget }\end{array}$ \\
\hline & Upper air:b & $\begin{array}{l}\text { Temperature, wind speed and direction, water vapor, cloud properties, Earth radiation } \\
\text { budget (including solar irradiance) }\end{array}$ \\
\hline & Composition & $\begin{array}{l}\text { Carbon dioxide, methane, other long-lived greenhouse gases, }{ }^{c} \text { ozone and aerosol } \\
\text { supported by their precursors }{ }^{d}\end{array}$ \\
\hline \multirow{2}{*}{ Oceanic } & Surface: ${ }^{e}$ & $\begin{array}{l}\text { Sea surface temperature, sea surface salinity, sea level, sea state, sea ice, surface } \\
\text { current, ocean color, carbon dioxide partial pressure, ocean acidity, phytoplankton }\end{array}$ \\
\hline & Subsurface: & $\begin{array}{l}\text { Temperature, salinity, current, nutrients, carbon dioxide partial pressure, ocean } \\
\text { acidity, oxygen, tracers }\end{array}$ \\
\hline Terrestrial & & $\begin{array}{l}\text { River discharge, water use, groundwater, lakes, snow cover, glaciers and ice caps, ice } \\
\text { sheets, permafrost, albedo, land cover (including vegetation type), fraction of absorbed } \\
\text { photosynthetically active radiation, leaf area index, above-ground biomass, soil carbon, } \\
\text { fire disturbance, soil moisture }\end{array}$ \\
\hline
\end{tabular}

${ }^{a}$ Including measurements at standardized but globally varying heights in close proximity to the surface.

b Up to the stratopause.

c Including $\mathrm{N}_{2} \mathrm{O}$, chlorofluorocarbons (CFCs), hydrochlorofluorocarbons (HCFCs), $\mathrm{SF}_{6}$, and perfluorocarbons (PFCs).

In particular $\mathrm{NO}_{2}, \mathrm{SO}_{2}, \mathrm{HCHO}$, and $\mathrm{CO}$.

e Including measurements within the surface mixed layer, usually within the upper $15 \mathrm{~m}$.

Subsequently, the international terrestrial community identified "key variables" describing the biosphere, hydrosphere, and cryosphere (GCOS 1997) based on measurement practicality and the priority for climate. These variables were deemed the minimal set for which data records were absolutely necessary, recognizing that other, "secondary" variables were also important for context or interpretation.

The expression "essential climate variables" was first introduced in GCOS (2003), spanning the atmospheric, oceanic, and terrestrial domains. In their response to this report, parties (signatory states) of the United Nations Framework Convention on Climate Change (UNFCCC) emphasized the principle of free and unrestricted exchange for ECV datasets, adopted an expanded set of GCOS climate monitoring principles, and requested the GCOS program to plan implementation (UNFCCC 2004).

Subsequent reporting and planning, starting with the first implementation plan (GCOS 2004), used

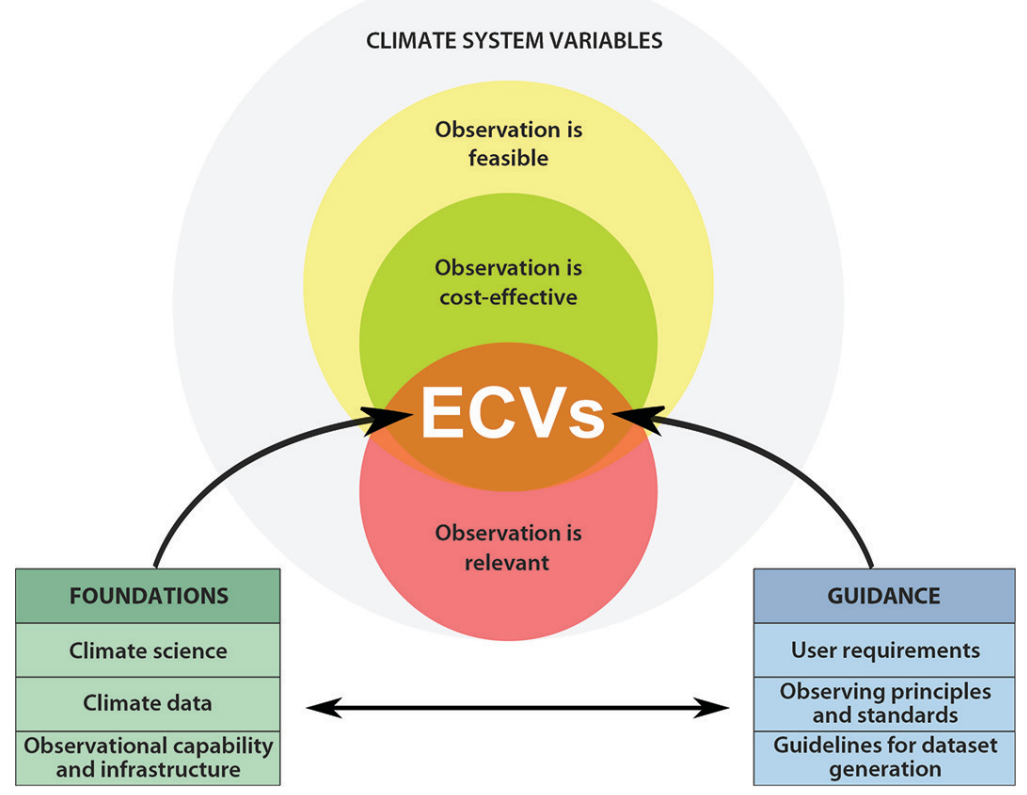

FIG. 2. Schematic of the ECV concept: knowing existing climaterelevant observing capabilities, climate datasets, and the level of scientific understanding of the climate system are the foundations (lower-left box) necessary for selecting the ECVs from a pool of climate system variables. In addition, guidance is needed to make practical use of the ECVs (lower-right box): user requirements capture the data quality needs of science, services, and policy; climatespecific principles guide the operation of observing systems and infrastructure; and guidelines facilitate the transparent generation of ECV data records. The latter address the availability of metadata, provisions for data curation and distribution, and the need for quality assessment and peer review. 
the ECVs as a guiding framework. Indicative requirements for accuracy, spatial and temporal resolution and other characteristics of ECV datasets were specified for satellite-based datasets (GCOS 2006, 2011). Guidelines were also developed for generating ECV data records in general, emphasizing the importance of calibration and validation, documentation, and self and independent assessments (GCOS 2010b). The 20 climate monitoring principles, developed based on the original set of 10 adopted by the UNFCCC in 1999, provide guidance for observing system operations (GCOS 2010a).

UPTAKE. Science and policy circles have widely endorsed the ECV concept. The parties to the UNFCCC acknowledged the need to act upon the plans for implementation (GCOS 2004, 2010a). Guidelines for their reporting on national programs contributing to global climate observation are structured along the ECVs (UNFCCC 2008). In its planning of global observation for weather, water, and climate applications, WMO addresses the ECVs and recognizes GCOS assessment and planning documents as statements of guidance.

The ECVs have been identified as a key element of the observations and monitoring pillar of the GFCS (WMO 2011a). European regulation on initial operation of environmental services within the Copernicus initiative [formerly Global Monitoring for Environment and Security (GMES)] builds upon the ECVs for its climate service component (European Union 2010). Some countries use the ECV concept to identify national climate observing networks and data records and to improve the legal and financial basis for continuity (Seiz and Foppa 2007).

Satellite agencies have responded strongly to the concept, through the Committee on Earth Observation Satellites (CEOS 2008) and more recently through the broadly developed Architecture for Climate Monitoring from Space (Dowell et al. 2013). ESA launched the Climate Change Initiative aimed at the generation of satellite-derived ECV datasets based on historical data holdings (Hollmann et al. 2013; ESA 2013). EUMETSAT (2011) responded by deriving ECV records (Schulz et al. 2009) and, along with the Japan Meteorological Agency, by reprocessing wind and other data from their geostationary satellites. Agencies from the United States, China, and other countries engage in related initiatives such as the Global SpaceBased Inter-Calibration System (GSICS; Hewison et al. 2013) and the Sustained, Coordinated Processing of Environmental Satellite Data for Climate Monitoring (SCOPE-CM; Lattanzio et al. 2013).
Annual statements on the state of the global climate are now structured around the ECVs (Blunden and Arndt 2013; this reference includes a range of average multidecadal ECV time series and a brief account of ECV provenance), and so is a recent report on global climate events during the decade of 2001-10 (WMO 2013). Most of the essential needs for sustained observation identified by the World Climate Research Programme (WCRP) and enabling the work of the Intergovernmental Panel on Climate Change (IPCC) are based on the ECVs (Doherty et al. 2009). Systematic assessment and evaluation of ECV datasets at the international level is a general need, and has begun (WCRP 2011; Stubenrauch et al. 2013).

In summary, identifying ECVs and associated guidance has encouraged scientists and observing system operators to put more focus on these variables. It has stimulated the engagement of national and international organizations and funding agencies to support work on the variables. It has also helped many nations to make commitments to support systematic, sustained climate records.

The variable-based approach has been adopted more broadly as a basis for prioritized requirements setting and focused, coordinated action. In particular, the ocean and biodiversity communities have identified essential ocean variables (UNESCO 2012) and essential biodiversity variables (Pereira et al. 2013). Furthermore, many ECVs may also be useful for addressing applications that are not directly climate related: for instance, in support of other societal benefit areas of the Global Earth Observation System of Systems (GEOSS; e.g., Hollingsworth et al. 2005).

DISCUSSION AND ILLUSTRATION. The ECV concept supports observing system planning, network design and operation, and climate dataset generation but is not without its challenges.

Observing system planning and resourcing. By their very nature, ECVs (or quantities closely related to them from which ECV datasets can be derived) must be observed as a matter of priority, in a way that meets requirements. The ECV concept guides the specification of observing networks and archiving systems and the arrangements for monitoring their performance. However, meeting climate standards implies continuing investments in instrumentation and in the generation, validation, and intercomparison of datasets. Existing infrastructure, often in support of weather forecasting, may need upgrading to meet the more exacting needs of some climate applications. Despite progress in recent years, much of the global 
infrastructure for acquiring and archiving climate observations and for delivering related climate datasets and services remains fragile and incomplete (GCOS 2009; WMO 2011a).

Further optimizing the design of an integrated global climate observing system remains important (Trenberth et al. 2012). The GCOS program recognized a hierarchy of observational networks and systems, comprising comprehensive, baseline, and reference networks (Houghton et al. 2012; Seidel et al. 2009) based on assumptions of spatial sampling needs (e.g., Peterson et al. 1997). However, a more systematic approach is needed to observing system design studies, including impact experiments, using guidance from the numerical weather prediction community (WMO 2012) and recognizing that many observations will continue to serve both weather and climate purposes. Such studies have to take account of intrinsic climate variability and limits to predictability (Meehl et al. 2009; Hoskins 2013).

Many research activities are important to systematic ECV observation since (i) they provide supplemental observations, (ii) they seek better ways of meeting targets for accuracy, and (iii) they pioneer capabilities to measure new variables. Yet, projects or systems based on research funding are generally not designed for transition to sustained monitoring of variables globally and over long time periods, often leading to partial, haphazard, intermittent coverage (Keeling 1998; Nisbet 2007; Wunsch et al. 2013). Recognition of variables as ECVs has helped alleviate issues and foster transition of research-based observational activities into a more sustained framework (e.g., WGMS 2008; ICOS 2013).

Generating ECV datasets. Long-term instrumentlevel datasets, such as satellite-based "fundamental climate data records" (calibrated datasets at nominal instrument-specific resolution), are the critical basis for generating ECV datasets. Many steps need to be carefully considered, for which GCOS (2010b) provides general guidance. Quality assessment and peer review of datasets are very important (see sidebar). Providers of climate datasets should, where possible, meet community-specific needs for representing data, such as in suitable gridded formats with information on uncertainty to facilitate model-observation comparisons (Gómez-Navarro et al. 2012).

Reanalysis. Reprocessing past observations of atmosphere, ocean and land using data assimilation methods as developed for numerical weather prediction and seasonal forecasting has become an important information source on recent climate variations (Dee et al. 2014) and for assessing climate models (Gleckler et al. 2008). Such reanalysis is both a consumer and, as featured in the State of the Climate report (Blunden and Arndt 2013), a contributor to ECV datasets. The European interim global reanalysis from 1979 (ERA-Interim), for example, provides datasets for atmospheric surface and upper-air ECVs and other ECVs such as ozone and ocean-wave state, but its assimilating model uses specified sea surface temperatures, sea ice concentrations, and various land surface fields and radiative gas distributions. Extension to provide analysis of atmospheric composition ECVs is discussed by Dee et al. (2014). Ocean and land reanalyses provide datasets on variables such as subsurface ocean temperature and soil moisture but in turn utilize meteorological forcing fields from atmospheric reanalysis or other sources. Capability for analyzing other domains continues to improve, as shown by Balmaseda et al. (2013) for ocean reanalysis, and, with further development of coupled data assimilation, the number of reanalysis-based ECV datasets is expected to rise.

The quality and applicability of the comprehensive ECV datasets provided by reanalysis vary geographically, with height, over time, and from one variable to another and can be difficult to quantify. For example, Compo et al. (2011) use ensemble data assimilation to estimate uncertainty associated with flow-dependent predictability, but this does not obviate the need for additional, observation-related diagnostic information that supplements gridded reanalysis datasets (Dee et al. 2011). Comparison of an ECV dataset from reanalysis with an alternative derived directly from observations as outlined in the sidebar can provide reassurance as to the quality of both (Simmons et al. 2010).

Examples for terrestrial ECVs. Many terrestrial ECVs, such as river runoff and soil moisture, are of vital direct societal importance, and many are inherently more heterogeneous than their atmospheric and oceanic counterparts. Establishing international coordination and measurement standards has been more difficult for terrestrial than for other ECVs. Yet, progress has been made (GCOS 2009) and benefits of designating variables as ECVs have been realized. Two examples are briefly discussed.

FAPAR. The fraction of absorbed photosynthetically active radiation (FAPAR) is a measure of the productivity of the continental biosphere and thus of utmost interest. Identification as an ECV helped focus the attention of the scientific community, and 
multiple teams developed methods to retrieve values from remote sensing in the solar spectral range. This led to the generation of multiple datasets, stimulated the organization of field campaigns to acquire in situ measurements, and prompted CEOS to address discrepancies in the context of its calibration and validation working group. Efforts to harmonize FAPAR datasets are ongoing (e.g., Ceccherini et al. 2013). Yet, despite intense research and sustained efforts to establish standards and best practices (e.g., on validation; Widlowski 2010), no institution has proposed to be or been identified to serve as the central point of contact for the worldwide compilation, archiving, and distribution of FAPAR datasets.

GLACIERS AND ICE CAPS. Glaciers and ice caps have been recognized as an ECV since they are clear indicators of climate change and important contributors to

\section{BUILDING ECV DATASETS FOR CLIMATE MONITORING}

0 ne key application to be addressed by the ECVs is climate monitoring: that is, assessing climate variability and change using long time series of observations. Building an ECV dataset suitable for monitoring is generally complex. Typical steps are as follows:

Assembling the data. This first step may be straightforward for some in situ ECV datasets where the observations have already been taken and assembled as part of large data collections (e.g., surface water vapor; Willett et al. 20I3). Alternately, it may involve analyzing satellite observations spanning a decade or more to extract broad-scale representations of upper-air temperature (Spencer and Christy 1990). Some ECVs, such as the long-lived and strongly infrared-absorbing perfluorocarbons (PFCs), may require new observing instrumentation for accurate monitoring (Miller et al. 2008) that can also be used to extend the ECV record into the past by assessing archived gas (Mühle et al. 2010). Additionally, ECVs such as surface temperature may require searching archives and digitizing historical paper records to improve spatial or temporal coverage (e.g., Peterson and Griffiths 1997).

Adjusting data to account for inhomogeneities. In addition to spurious errors in individual data values, which good quality-control tests can remove, there are few long-term ECV observations that do not suffer from inhomogeneities unrelated to climate. Examples are drifts in satellite orbits over time and changes in observing practice: for example, ship-based sea surface temperature observations changed from putting thermometers in buckets that had been tossed overboard to haul up water from the surface of the ocean to thermometers being placed in engine cooling water intakes, which, for large ships, are typically located $5-15 \mathrm{~m}$ below the surface (Kent and Kaplan 2006). There exist many techniques to adjust climate time series data to account for such artificial inhomogeneities (e.g., Aguilar et al. 2003).

Real-time updates. Regular updates of an ECV dataset are required if the dataset is to be used for monitoring changes in the ECV. Operationally updating a dataset is a very different process requiring different skill sets than conducting the homogeneity research. It also marks the transition from research to operations.

Postproduction quality assurance. There are many different aspects to this stage. It often involves scrutinizing the data to assess particular characteristics of the ECV record. For example, for surface temperature, do rural stations indicate the same changes as the dataset as a whole (e.g., Peterson et al. 1999)? Or do permafrost temperatures increase when winter air temperatures increase (e.g., Smith et al. 2012)? Did sensor degradation or aerosols from volcanic eruptions artificially change a satellite-derived leaf area index (Los et al. 2000)? This stage also involves evaluating real-time updates to correct for other errors: for example, in the metadata (Lawrimore et al. 20II).

Documentation and transparency. As the IPCC Fourth Assessment Report states, "scientists usually submit their research findings to the scrutiny of their peers, which includes disclosing the methods that they use, so their results can be checked through replication by other scientists" (Le Treut et al. 2007, p. 95). However, given the central role that ECVs are increasingly having in monitoring the global climate, a higher level of transparency is generally expected to ensure credibility, as stated in the introduction. For example, rather than just providing the data and describing the algorithms used to produce the dataset, providing public access to the actual computer code used to make the ECV dataset is now part of what is considered best practice (Bates and Privette 20I2).

More than one dataset per ECV is required. After over a decade of producing an upper-air temperature record, with a series of successive improvements (Christy et al. 2003), another group undertook the creation of a satellite-derived record for this ECV. In the process of producing their version (Mears et al. 2003), they uncovered an error in the first group's adjustment to account for satellite drift, an error that changed the sign of the adjustment (Thorne et al. 2010). This example illustrates that the best proof of quality is having several independent groups producing their own versions of ECV datasets, ideally using different methodologies, as this would help quantify the structural uncertainty in the ECV records as well as provide an objective, empirical corroboration of the results (Folland et al. 2006).

Monitoring the ECV. A key need is to understand how the ECVs are changing. The State of the Climate report (Blunden and Arndt 2013) provides an annual reference based on a large community effort that assesses change for many ECVs and other climatic variables. Not only does coauthoring that paper provide an opportunity for scientists to update their results annually but, because the report includes multiple alternative ECV datasets wherever possible, it allows ready comparison of the results of different groups. 
global sea level changes, regional water cycles, and local hazards. Changes in glacier length, area, volume, and mass are the key variables. Records date back to the seventeenth century and transnational compilations of such data were initiated in the late nineteenth century (WGMS 2008). Loss of glacier mass due to surface air temperature and precipitation changes contributes an estimated 30\% to total observed sea level change (Gardner et al. 2013), underscoring the need to understand and observe the physical interplay of atmospheric, ocean, and terrestrial ECVs.

Recognizing glaciers as an ECV has helped secure sustained funding for the World Glacier Monitoring Service (WGMS) and additional funding for capacity building promoting the resumption of systematic observation in some countries (MeteoSwiss 2013). Terminology standards and best observational practices have also been developed (Cogley et al. 2011; Zemp et al. 2013).

Essential fluxes. It has been proposed that fluxes (e.g., of energy, water, carbon) be included in the ECV list, mainly since they are essential for understanding the cyclical processes of the climate system. Fluxes can sometimes be derived from measured gradients of ECVs: for example, by analyzing atmospheric humidity profiles obtained from soundings or by eddy covariance measurements of trace gases. Generally and especially at large scales, however, fluxes are not directly observable. They are inferred from a combination of observations, model simulations and assumptions about the permeability of interfaces: for example, for estimating the net flux of methane over permafrost areas using biogeochemical models and observations (Zhang et al. 2012). Clearer focus on how to quantify these fluxes and to agree on consistent terminology and measurement principles should improve the description of exchange processes at interfaces and facilitate understanding of biogeochemical cycles.

Consistency of the ECV list. Consistently applying the selection criteria for ECVs has been a challenge because of their diversity. This extends to adding or removing variables: the importance of many other variables has long been recognized (GCOS 1997 identified as many as 70 key variables to characterize land surfaces), but their adoption as ECVs has been hampered by other considerations: for instance, in the case of land surface temperature, complexity of interpretation, and limited utility for climate monitoring. Some variables have been initially "carried over" as ECVs because of their historical importance and availability, though they might not have been selected in the absence of such a legacy (e.g., chlorophyll concentration in the top ocean layer).

Diverse requirements. Different observation requirements for the same ECV from different application communities need to be recognized and reconciled, where possible. For example, numerical weather forecasting and seasonal prediction require nearreal-time access to observations of atmospheric and surface variables to optimally predict (possibly extreme) events. Some of the variables may also be of great interest for climate adaptation or trend studies. These applications have quite different requirements for spatial and temporal resolution, timeliness of data delivery, absolute accuracy, measurement stability, and length of data record.

Similarly, requirements for biological variables such as the leaf area index, which measures the surface of leaf material in plant canopies, are quite different for constraining a climate model than for managing agricultural systems against a regional climate change backdrop: horizontal resolution of global climate models is generally on the order of $50 \mathrm{~km}$ and would require a leaf area index dataset at this order of spatial resolution, whereas, for agricultural management, details on a resolution as fine as $1 \mathrm{~km}$ or less may be necessary. In the same vein, requirements for measuring air temperature for estimating urban heat stress differ from those for quantifying multidecadal trends in regional temperature.

Moreover, the thematic separation of ECVs into three geophysical domains has led to the setting of somewhat incompatible specifications for variables that are physically linked. For example, in GCOS (2011) observational requirements set for the ECV "surface albedo" (a joint property of the land and the overlying atmosphere; GCOS 2007; Lattanzio et al. 2013) are not compatible with the requirements set for aerosols and clouds, which are drivers of the atmospheric radiative properties. Such inconsistencies require further attention.

\section{HOW SHOULD THE ECV CONCEPT EVOLVE? The ECV concept has proven useful} to scientists, observing system operators, program planners, and policymakers, but issues related to consistency, data curation, resources, requirements, and review of the ECV concept have been identified. How should the concept evolve over the coming decades? The following paragraphs discuss additional drivers for a progressive evolution and a process for managing it. 
Data curation and stewardship. Many communities have risen to the challenge of long-term data management and stewardship. They have designed and built unique, worldwide facilities to preserve essential heritage information in their respective fields, including seed banks to preserve biodiversity (Fowler 2008), powerful data infrastructures to support large-scale particle physics experiments (Bird 2011), and the UNESCO world cultural heritage record (UNESCO 1972). Such facilities require institutional commitments, agreements on sharing resources, and common data management standards.

Elements of a global infrastructure for climate dataset curation and stewardship are in place, partly based on data centers recognized within the ICSU World Data System (ICSU 2013). However, the data policies of many providers still prevent free and open data access to ECV datasets, despite progress in response to repeated calls for change (Uhlir et al. 2009). Intellectual property issues that compromise open access to climate records (Nelson 2009) should be overcome by introducing data identifiers [e.g., digital object identifiers (DOIs)] as standard practice, thus incentivizing data sharing through recognition of authorship. Restrictions stemming from a perceived commercial or strategic value of climate data are more difficult to resolve.

Also, although the Global Observing Systems Information Center data portal hosted by the U.S. National Climatic Data Center (www.gosic.org) facilitates discovery and access to ECV products, gaps remain in providing single access points to well-documented datasets in common data formats for the complete range of ECVs. New cost-sharing arrangements to ensure long-term stewardship (e.g., by levying observation activities) should be explored.

Broadening the Earth observation basis. Over the coming decade, wider availability of low-cost sensor technology will contribute to higher spatial and temporal sampling of the near-surface environment (e.g., through deployment in urban environments, transport vehicles, drones, or "citizen observations"). Although tradeoffs between data quality and volume will have to be made, such observations could be beneficial for tracking impacts of or exposure to climatic and other environmental hazards and thereby help building ECV datasets. Broad deployment of observing technology could also raise public awareness of environmental monitoring and eventually lead to smarter environmental decision making.

Beyond climate. Today's climate models still have limited representations of the biogeochemical cycles (notably carbon). Decades from now, global models of the Earth system will likely simulate agricultural and industrial production, transport, consumption, economic flows, and demography. Socioeconomic variables such as gross domestic product, rate of mortality, disease incidence, and transport routes would be considered to be as essential as the current set of physical, chemical, and biological variables. Data on some of these socioeconomic variables are already needed to model anthropogenic emissions of greenhouse gases and other pollutants, to monitor and control other environmental risks, and to provide climate services. Much more will be needed as modeling capabilities expand. Progress in data assimilation and observation technology is expected to go hand in hand with this development. Climate and environment information will become increasingly important for understanding and predicting the evolution of markets and influence financial strategies. These communities may evolve from mere customers of information to also directly supporting the generation, archiving and distribution of basic data.

Process. Given its broad uptake, further development of the ECV concept needs to be well managed, based on regular reviews and updates of guidance. The process that has been developed by the GCOS program involves a variable-based assessment and implementation cycle that is shown in generic, schematic form in Fig. 3. It builds on the existence of an identified pool of climate-relevant variables: the ECVs and other variables that are candidates for consideration as ECVs depending on relevance, feasibility, and cost effectiveness. The cycle comprises the following:

- assessment of adequacy of observing systems, ECV datasets, and scientific and technological developments (the foundations in Fig. 2), with implications for the list of ECVs;

- implementation planning based on an updated set of ECVs and guidance material (guidance in Fig. 2), identifying the required actions related to observing system design, dataset generation, and data stewardship; and

- responses by the agents for implementation (e.g., observing system operators), seen most immediately by users in the generation and exploitation of datasets that underpin products, user applications, and services.

Figure 3 goes beyond current GCOS practice in also recognizing that some data records should be 
designated to be part of the climate heritage record and should be preserved in dedicated archives. The heritage record should include datasets that have been superseded by new science or technology; where possible, these datasets should be maintained in parallel with new observations during a period of overlap sufficient to ensure a traceable record, and some should be continued for as long as they usefully serve as a baseline for climate assessments.

The GCOS reporting and planning documents that result from the assessment and implementation cycle are based on broad community engagement. This involves scientific workshops that draw on lessons learned from the IPCC assessment process; scrutiny by its cosponsored expert panels for atmosphere, ocean, and land (Houghton et al. 2012); open public review and response to comments; and formal acceptance by the Steering Committee for GCOS, to which members are appointed by the program sponsors.

The process gains legitimacy through acceptance by the sponsors, the parties to the UNFCCC, and others, including the various national and international agents for implementation without whom progress could not be made.

The essential character of the ECV list has been one of its strengths, calling for prudence in its expansion. The roughly 6-yr period adopted by GCOS for the cycle illustrated in Fig. 3 has tended to follow that of the IPCC assessment reports, though arguably it should be a little longer. Observation requirements for ECV datasets must recognize the needs of the range of applications. Although a holistic approach to setting them is desirable, the user requirements for ECV datasets will not in general be consistent among each other. In any case, GCOS requirements are of indicative nature, and more refined user requirements have to be developed for specific observing missions and dataset generation initiatives (e.g., Hollmann et al. 2013).

Addition of fluxes and socioeconomic variables to the ECVs would require a departure from the current distinction by geophysical domains. Questions to address would include, for example, whether the GCOS climate monitoring principles can be straightforwardly adapted to guide observing systems for socioeconomic parameters or whether the same principles for dataset documentation and reprocessing can be applied to datasets describing population and wealth distribution. Ways of defining and presenting the ECV concept will have to evolve.

IN CONCLUSION. The ECV concept has been successful and should continue to guide the observation community in enabling evidence-based climate monitoring, science, and services. The ECV concept addresses public demands for transparency in environmental decision making (UN 2012; Major Groups 2012). We nevertheless realize the limits to rationality and objectivity in such decisions (Nilsson and Dalkmann 2001), even if optimal observationbased evidence (e.g., for environmental degradation) is available.

The ECV concept is flexible vis à vis changing priorities, application needs, and scientific and technological innovation. Priorities remain essential; the ECV concept has provided guidance in this regard. It may serve as a blueprint for communities of practice in other societal benefit areas of the GEOSS as they assess evolving data needs and required actions for observing the Earth system. 
The climate community at large is invited to participate in the discussion of further evolution of the ECV concept. The process lives from consensus and active participation. Strong connections to those involved in climate research, particularly through the WCRP, and in applications remain essential. The GCOS program has already begun a new assessment phase, which will draw in part on conclusions drawn from the IPCC Fifth Assessment Report. Based on its evaluation of progress and adequacy, the next issue of the implementation plan for the global observing system for climate will be developed for 2016. The GCOS Secretariat (gcosjpo@wmo.int) should be contacted for further information.

ACKNOWLEDGMENTS. We thank Paul Mason, who led the development of many of the key GCOS documents contributing to the ECV concept. We also thank Alan Belward, Eric Lindstrom, and reviewers for comments on earlier versions of this article.

\section{REFERENCES}

Aguilar, E., I. Auer, M. Brunet, T. C. Peterson, and J. Wieringa, 2003: Guidelines on climate metadata and homogenization. WCDMP Tech Doc. 53, WMO Tech. Doc. 1186, 55 pp.

Balmaseda, M. A., K. Mogensen, and A. T. Weaver, 2013: Evaluation of the ECMWF ocean reanalysis system ORAS4. Quart. J. Roy. Meteor. Soc., 139, 1132-1161, doi:10.1002/qj.2063.

Bates, J. J., and J. L. Privette, 2012: A maturity model for assessing the completeness of climate data records. Eos, Trans. Amer. Geophys. Union, 93, 441, doi:10.1029/2012EO440006.

Bird, I., 2011: Computing for the Large Hadron Collider. Ann. Rev. Nucl. Part. Sci., 61, 99-118, doi:10.1146 /annurev-nucl-102010-130059.

Blunden, J., and D. S. Arndt, Eds., 2013: State of the climate in 2012. Bull. Amer. Meteor. Soc., 94 (Suppl.), S1-S238, doi:10.1175/2013BAMSStateoftheClimate.1.

Ceccherini, G., N. Gobron, and M. Robustelli, 2013: Harmonization of fraction of absorbed photosynthetically active radiation (FAPAR) from Sea-Viewing Wide Field-of-View Sensor (SeaWiFS) and Medium Resolution Imaging Spectrometer Instrument (MERIS). Remote Sens., 5, 3357-3376, doi:10.3390/rs5073357.

CEOS, 2008: The Earth observation handbook: Climate change special edition 2008. ESA Rep. SP-1315, 265 pp.

Christy, J. R., R. W. Spencer, W. B. Norris, W. D. Braswell, and D. E. Parker, 2003: Error estimates of version 5.0 of MSU-AMSU bulk atmospheric temperatures. J. Atmos. Oceanic Technol., 20, 613-629, doi:10.1175/1520-0426(2003)202.0.CO;2.

Cogley, J. G., and Coauthors, 2011: Glossary of glacier mass balance and related terms. IHP-VII Hydrology Tech. Doc. 86, IACS Contribution 2, 114 pp. [Available online at http://unesdoc.unesco.org /images/0019/001925/192525e.pdf.]

Compo, G. P., and Coauthors, 2011: The Twentieth Century Reanalysis Project. Quart. J. Roy. Meteor. Soc., 137, 1-28, doi:10.1002/qj.776.

Dee, D. P., E. Källén, A. J. Simmons, and L. Haimberger, 2011: Comments on "Reanalyses suitable for characterizing long-term trends." Bull. Amer. Meteor. Soc., 92, 65-70, doi:10.1175/2010BAMS3070.1.

—, M. Balmaseda, G. Balsamo, R. Engelen, A. J. Simmons, and J.-N. Thépaut, 2014: Toward a consistent reanalysis of the climate system. Bull. Amer. Meteor. Soc., in press, doi:10.1175/BAMS -D-13-00043.1.

Doherty, S. J., and Coauthors, 2009: Lessons learned from the IPCC AR4: Scientific developments needed to understand, predict, and respond to climate change. Bull. Amer. Meteor. Soc., 90, 497-513, doi:10.1175/2008BAMS2643.1.

Dowell, M., and Coauthors, 2013: Strategy towards an architecture for climate monitoring from space. CEOS, WMO, and CGMS Rep., 39 pp. [Available online at www.wmo.int/pages/prog/sat/documents /ARCH_strategy-climate-architecture-space.pdf.]

ESA, 2013: Response by ESA to GCOS-Results of the climate change initiative requirements analysis. ESA Rep. CCI-PRGM-EOPS-TN-13-0008, 84 pp. [Available online at http://46.137.76.174/?q=webfm _send/80.]

EUMETSAT, 2011: EUMETSAT strategy: A global operational satellite agency at the heart of Europe. EUMETSAT Rep. COR.02-v1, 28 pp. [Available online at www.eumetsat.int/website/wcm/idc $/$ idcplg?IdcService $=$ GET_FILE\&dDocName $=$ PDF _BR_COR02_EN\&RevisionSelection Method $=$ LatestReleased $\&$ Rendition $=$ Web.]

European Union, 2010: Regulation (EU) No 911/2010 of the European Parliament and of the council of 22 September 2010 on the European Earth monitoring programme (GMES) and its initial operations (2011 to 2013). EU Doc. OJ L 276, 20.10.2010, 10 pp [Available online at http://eur-lex.europa.eu/LexUriServ /LexUriServ.do?uri=CELEX:32010R0911:EN:NOT.] Folland, C. K., D. Parker, R. W. Reynolds, S. C. Sherwood, and P. W. Thorne, 2006: What measures can be taken to improve the understanding of observed changes? Temperature trends in the lower atmosphere: Steps for understanding and reconciling 
differences, T. R. Karl et al., Eds., Climate Change Science Program and the Subcommittee on Global Change Research Rep., 119-128.

Fowler, C., 2008: The Svalbard Global Seed Vault: Securing the future for agriculture. Global Crop Diversity Trust Rep., 28 pp. [Available online at www .croptrust.org/documents/Svalbard\%20opening /New\%20EMBARGOED-Global\%20Crop\%20 Diversity\%20Trust\%20Svalbard\%20Paper.pdf.]

Gardner, A. S., and Coauthors, 2013: A reconciled estimate of glacier contributions to sea level rise: 2003 to 2009. Science, 340, 852-857, doi:10.1126 /science.1234532.

GCOS, 1995: Plan for the Global Climate Observing System, version 1.0. GCOS Rep. 14, 49 pp. [Available online at www.wmo.int/pages/prog/gcos/Publications /gcos-14.pdf.]

— 1997: GCOS/GTOS plan for terrestrial climaterelated observations, version 2.0. GCOS Rep. 32, 130 pp. [Available online at www.wmo.int/pages/prog /gcos/Publications/gcos-32.pdf.]

- 2003: Second report on the adequacy of the global observing systems for climate in support of the UNFCCC. GCOS Rep. 82, 85 pp. [Available online at www.wmo.int/pages/prog/gcos/Publications/gcos -82_2AR.pdf.]

_ 2004: Implementation plan for the global observing system for climate in support of the UNFCCC. GCOS Rep. 92, 153 pp. [Available online at www .wmo.int/pages/prog/gcos/Publications/gcos -92_GIP.pdf.]

__, 2006: Systematic Observation requirements for satellite-based products for climate: Supplemental details to the satellite-based component of the implementation plan for the global observing system for climate in support of the UNFCCC. GCOS Rep. 107, 103 pp. [Available online at www.wmo.int/pages /prog/gcos/Publications/gcos-107.pdf.]

— 2007: GCOS AOPC/TOPC Joint Working Group on Land-Surface/Atmosphere Issues (WG-LSA). GCOS Tech. Paper 1, 18 pp. [Available online at www .wmo.int/pages/prog/gcos/Publications/GCOS-TP1 .pdf.]

— 2009: Progress report on the implementation of the global observing system for climate in support of the UNFCCC 2004-2008. GCOS Rep. 129, 112 pp. [Available online at www.wmo.int/pages/prog/gcos /Publications/gcos-129.pdf.]

_- 2010a: Implementation plan for the global observing system for climate in support of the UNFCCC (2010 update). GCOS Rep. 138, 186 pp. [Available online at www.wmo.int/pages/prog/gcos /Publications/gcos-138.pdf.]
_ 2010b: Guideline for the generation of datasets and products meeting GCOS requirements. GCOS Rep. 143, 12 pp. [Available online at www.wmo.int/pages /prog/gcos/Publications/gcos-143.pdf.]

_- 2011: Systematic observation requirements for satellite-based products for climate 2011 update: Supplemental details to the satellite-based component of the "Implementation plan for the global observing system for climate in support of the UNFCCC (2010 update). GCOS Rep. 154, 138 pp. [Available online at www .wmo.int/pages/prog/gcos/Publications/gcos-154.pdf.]

Gleckler, P., K. E. Taylor, and C. Doutriaux, 2008: Performance metrics for climate models. J. Geophys. Res., 113, D06104, doi:10.1029/2007JD008972.

Gómez-Navarro, J. J., J. P. Montávez, S. Jerez, P. JiménezGuerrero, and E. Zorita, 2012: What is the role of the observational dataset in the evaluation and scoring of climate models? Geophys. Res. Lett., 39, L24701, doi:10.1029/2012GL054206.

Hewison, T., X. Wu, F. Yu, Y. Tahara, X. Hu, D. Kim, and M. Koenig, 2013: GSICS inter-calibration of infrared channels of geostationary imagers using Metop/IASI. IEEE Trans. Geosci. Remote Sens., 51, 1160-1170, doi:10.1109/TGRS.2013.2238544.

Hollingsworth, A., and Coauthors, 2005: The transformation of earth-system observations into information of socio-economic value in GEOSS. Quart. J. Roy. Meteor. Soc., 131, 3493-3512, doi:10.1256/qj.05.181.

Hollmann, R., and Coauthors, 2013: The ESA climate change initiative: Satellite data records for essential climate variables. Bull. Amer. Meteor. Soc., 94, 1541-1552, doi:10.1175/BAMS-D-11-00254.1.

Hoskins, B., 2013: The potential for skill across the range of the seamless weather-climate prediction problem: A stimulus for our science. Quart. J. Roy. Meteor. Soc., 139, 573-584, doi:10.1002/qj.1991.

Houghton, J., J. Townshend, K. Dawson, P. Mason, J. Zillman, and A. Simmons, 2012: The GCOS at 20 years: the origin, achievement and future development of the Global Climate Observing System. Weather, 67 (9), doi:10.1002/wea.1964.

ICOS, 2013: A European infrastructure dedicated to high-precision monitoring of greenhouse gas fluxes. Integrated Carbon Observation System Rep., $4 \mathrm{pp}$. [Available online at www.icos-infrastructure .eu/sites/icos-infrastructure-transition.eu/files /Icos4pager_06_03_2012.pdf.]

ICSU, 2013: ICSU World Data System Implementation Plan 2014-2018, 10 pp, [Available online at www .icsu-wds.org/files/wds-strategic-plan-201420132018.]

Karl, T., Ed., 1996: Long-Term Climate Monitoring by the Global Climate Observing System. Kluwer Academic, $518 \mathrm{pp}$. 
Keeling, C. D., 1998: Rewards and penalties of monitoring the earth. Annu. Rev. Energy Environ., 23, 25-82, doi:10.1146/annurev.energy.23.1.25.

Kent, E. C., and A. Kaplan, 2006: Toward estimating climatic trends in SST. Part III: Systematic biases. J. Atmos. Oceanic Technol., 23, 487-500, doi:10.1175 /JTECH1845.1.

Lattanzio, A., and Coauthors, 2013: Land surface albedo from geostationary satellites: A multiagency collaboration within SCOPE-CM. Bull. Amer. Meteor. Soc., 94, 205-214, doi:10.1175/BAMS-D-11-00230.1.

Lawrimore, J. H., M. J. Menne, B. E. Gleason, C. N. Williams, D. B. Wuertz, R. S. Vose, and J. Rennie, 2011: An overview of the Global Historical Climatology Network monthly mean temperature data set, version 3. J. Geophys. Res., 116, D19121, doi:10.1029/2011JD016187.

Le Treut, H., R. Somerville, U. Cubasch, Y. Ding, C. Mauritzen, A. Mokssit, T. Peterson, and M. Prather, 2007: Historical overview of climate change. Climate Change 2007: The Physical Science Basis, S. Solomon et al., Eds., Cambridge University Press, 93-127.

Los, S. O., and Coauthors, 2000: A global 9-yr biophysical land surface dataset from NOAA AVHRR data. J. Hydrometeor., 1, 183-199, doi:10.1175/1525 -7541(2000)0012.0.CO;2.

Major Groups, 2012: Rio+20 common statement. Stakeholder Forum of the Earth Summit 2012 Discussion Paper, 2 pp. [Available online at www .stakeholderforum.org/fileadmin/files/Major\%20 Groups\%20common\%20statement.pdf.]

Mears, C. A., M. C. Schabel, and F. J. Wentz, 2003: A reanalysis of the MSU channel 2 tropospheric temperature record. J. Climate, 16, 3650-3664, doi:10.1175/1520-0442(2003)0162.0.CO;2.

Meehl, G. A., and Coauthors, 2009: Decadal prediction: Can it be skillful? Bull. Amer. Meteor. Soc., 90, 1467-1485, doi:10.1175/2009BAMS2778.1.

MeteoSwiss, cited 2013: Capacity Building and Twinning for Climate Observing Systems (CATCOS)Glacier monitoring. [Available online at www .meteoschweiz.admin.ch/web/en/meteoswiss /international_affairs/international_projects /CATCOS/terrestrial_domain.html.]

Miller, B. R., R. F. Weiss, P. K. Salmeh, T. Tanhua, B. R. Greally, J. Mühle, and P. G. Simmonds, 2008: Medusa: A sample preconcentration and GC/MS detector system for in situ measurements of atmospheric trace halocarbons, hydrocarbons, and sulfur compounds. Anal. Chem., 80, 1536-1545, doi:10.1021/ac702084k.

Mühle, J., A. L. and Coauthors, 2010: Perfluorocarbons in the global atmosphere: Tetrafluoromethane, hexafluoroethane, and octafluoropropane. Atmos. Chem. Phys., 10, 5145-5164, doi:10.5194/acp-10 -5145-2010.

Nelson, B., 2009: Empty archives. Nature, 461, 160-163, doi:10.1038/461160a.

Nilsson, M., and H. Dalkmann, 2001: Decision making and strategic environmental assessment. J. Environ. Assess. Policy Manage., 3, 305, doi:10.1142/S1464333201000728.

Nisbet, E., 2007: Cinderella science. Nature, 450, 789-790, doi:10.1038/450789a.

NRC, 1994: Ocean-Atmosphere Observations Supporting Short-Term Climate Predictions. National Academy Press, $51 \mathrm{pp}$.

Pereira, H. M., and Coauthors, 2013: Essential biodiversity variables. Science, 339, 277-278, doi:10.1126 /science.1229931.

Peterson, T. C., and J. F. Griffiths, 1997: Historical African data. Bull. Amer. Meteor. Soc., 78, 2869-2872.

,- H. Daan, and P. Jones, 1997: Initial selection of a GCOS surface network. Bull. Amer. Meteor. Soc., 78, 2145-2152, doi:10.1175/1520-0477(1997)0782.0.CO;2.

— K. K. Gallo, J. Lawrimore, T. W. Owen, A. Huang, and D. A. McKittrick, 1999: Global rural temperature trends. Geophys. Res. Lett., 26, 329-332, doi:10.1029/1998GL900322.

Schulz, J., and Coauthors, 2009: Operational climate monitoring from space: The EUMETSAT Satellite Application Facility on Climate Monitoring (CMSAF). Atmos. Chem. Phys., 9, 1687-1709, doi:10.5194 lacp-9-1687-2009.

Seidel, D. J., and Coauthors, 2009: Reference upperair observations for climate: Rationale, progress, and plans. Bull. Amer. Meteor. Soc., 90, 361-369, doi:10.1175/2008BAMS2540.1.

Seiz, G., and N. Foppa, 2007: National Climate Observing System. MeteoSwiss and ProClim Rep., 95 pp. [Available online at www.meteosuisse.admin .ch/web/en/meteoswiss/international_affairs/gcos /uebersicht_klimabeobachtung/nationales _klimabeobachtungssystem.Par.0027.DownloadFile .tmp/nationalclimateobservingsystem.pdf.]

Shapiro, M., and Coauthors, 2010: An Earth-system prediction initiative for the twenty-first century. Bull. Amer. Meteor. Soc., 91, 1377-1388, doi:10.1175/2010BAMS2944.1.

Simmons, A. J., K. M. Willett, P. D. Jones, P. W. Thorne, and D. P. Dee, 2010: Low-frequency variations in surface atmospheric humidity, temperature, and precipitation: Inferences from reanalyses and monthly gridded observational data sets. J. Geophys. Res., 115, D01110, doi:10.1029/2009JD012442.

Smith, S. L., J. Throop, and A. G. Lewkowicz, 2012: Recent changes in climate and permafrost temperatures 
at forested and polar desert sites in northern Canada. Can. J. Earth Sci., 49, 914-924, doi:10.1139/e2012-019.

Spencer, R. W., and J. R. Christy, 1990: Precise monitoring of global temperature trends from satellites. Science, 247, 1558-1562, doi:10.1126/science.247.4950.1558.

Stubenrauch, C. J., and Coauthors, 2013: Assessment of global cloud datasets from satellites: Project and database initiated by the GEWEX Radiation Panel. Bull. Amer. Meteor. Soc., 94, 1031-1049, doi:10.1175 /BAMS-D-12-00117.1.

Thorne, P. W., J. R. Lanzante, T. C. Peterson, D. J. Seidel, and K. P. Shine, 2010: Tropospheric temperature trends: History of an ongoing controversy. Wiley Interdiscip. Rev.: Climate Change, 2, 66-88, doi:10.1002/wcc.80.

Trenberth, K. E., 1995: Long-term climate monitoring by the Global Climate Observing System. Climatic Change, 31, 163-180, doi:10.1007/BF01095144.

— climate observing system. Climate Science for Serving Society: Research, Modelling and Prediction Priorities, J. W. Hurrell and G. Asrar, Eds., Springer, 485 pp.

Uhlir, P. F., R. S. Chen, J. I. Gabrynowicz, and K. Janssen, 2009: Towards implementation of the Global Earth Observation System of Systems data sharing principles. J. Space Law, 35, 201-290.

UN, cited 2012: The future we want. - United Nations General Assembly Resolution 66/288. [Available online at http://sustainabledevelopment.un.org /futurewewant.html.]

UNESCO, 1972: Convention concerning the protection of the world cultural and natural heritage. United Nations Educational, Scientific and Cultural Organisation, $17 \mathrm{pp}$. [Available online at http://whc.unesco .org/archive/convention-en.pdf.]

—, 2012: Framework for ocean observing. Task Team for an Integrated Framework for Sustained Ocean Observing Rep. INF-1284, 28 pp, doi:10.5270 /OceanObs09-FOO.

UNFCCC, 2004: Global observing systems for climate. Report of the Conference of the Parties on its ninth session, held at Milan from 1 to 12 December 2003, 20-22 [Available online at http://unfccc.int/resource /docs/cop9/06a01.pdf\#page=20.]

_ 2008 : Reporting on global observing systems for climate. Report of the Conference of the Parties on its thirteenth session, held in Bali from 3 to 15 December 2007, 17 pp. [Available online at http://unfccc.int /resource/docs/2007/cop13/eng/06a02.pdf\#page $=1$.

WCRP, 2011: Report of WOAP Workshop on Evaluation of Satellite-Related Global Climate Datasets. WCRP
Informal Rep. 33/2011, GCOS-153, 44 pp. [Available online at http://wcrp-climate.org/documents /ECV_Wksp_WCRP_Report.pdf.]

WGMS, 2008: Global glacier changes: Facts and figures. UNEP World Glacier Monitoring Service Rep., 88 pp. [Available online at www.grid.unep.ch/glaciers /pdfs/glaciers.pdf.]

Widlowski, J.-L., 2010: On the bias of instantaneous FAPAR estimates in open-canopy forests. Agric. For. Meteor., 150, 1501-1522, doi:10.1016/j .agrformet.2010.07.011.

Willett, K. M., C. N. Williams Jr., R. J. H. Dunn, P. W. Thorne, S. Bell, M. de Podesta, P. D. Jones, and D. E. Parker, 2013: HadISDH: an updateable land surface specific humidity product for climate monitoring. Climate Past, 9, 657-677, doi:10.5194/cp-9-657-2013. WMO, 2009: Better climate information for a better future. WMO Secretariat World Climate Conference-3 Third Announcement, 24 pp.

— , 2011a: Climate knowledge for action: A global framework for climate services, empowering the most vulnerable. World Meteorological Organization Rep. 1065, 248 pp. [Available online at www.wmo.int /hlt-gfcs/downloads/HLT_book_full.pdf.]

_, 2011 b: Guide to climatological practices. World Meteorological Organization Rep. 100, 117 pp. [Available online at www.wmo.int/pages/prog/wcp /ccl/documents/WMO_100_en.pdf.]

_ , 2012: WMO Integrated Global Observing SystemFinal report of the Fifth WMO Workshop on the Impact of Various Observing Systems on Numerical Weather Prediction. WMO Tech. Rep. 2012-1, 25 pp. [Available online at www.wmo.int/pages/prog/www/OSY /Meetings/NWP5_Sedona2012/Final_Report.pdf.]

_ , 2013: The global climate 2001-2010: A decade of climate extremes. World Meteorological Organization Rep. 1103, 119 pp. [Available online at http:// library.wmo.int/pmb_ged/wmo_1103_en.pdf.]

Wunsch, C., R. W. Schmitt, and D. J. Baker, 2013: Climate change as an intergenerational problem. Proc. Natl. Acad. Sci. USA, 110, 4435-4436, doi:10.1073 /pnas.1302536110.

Zemp, M., and Coauthors, 2013: Reanalysing glacier mass balance measurement series. Cryosphere, 7, 1227-1245, doi:10.5194/tc-7-1227-2013.

Zhang Y., T. Sachs, C. Li, and J. Boike, 2012. Upscaling methane fluxes from closed chambers to eddy covariance based on a permafrost biogeochemistry integrated model. Global Change Biol., 18, 14281440, doi:10.1111/j.1365-2486.2011.02587.x. 


\section{$\infty$ the AMS online bookstore}

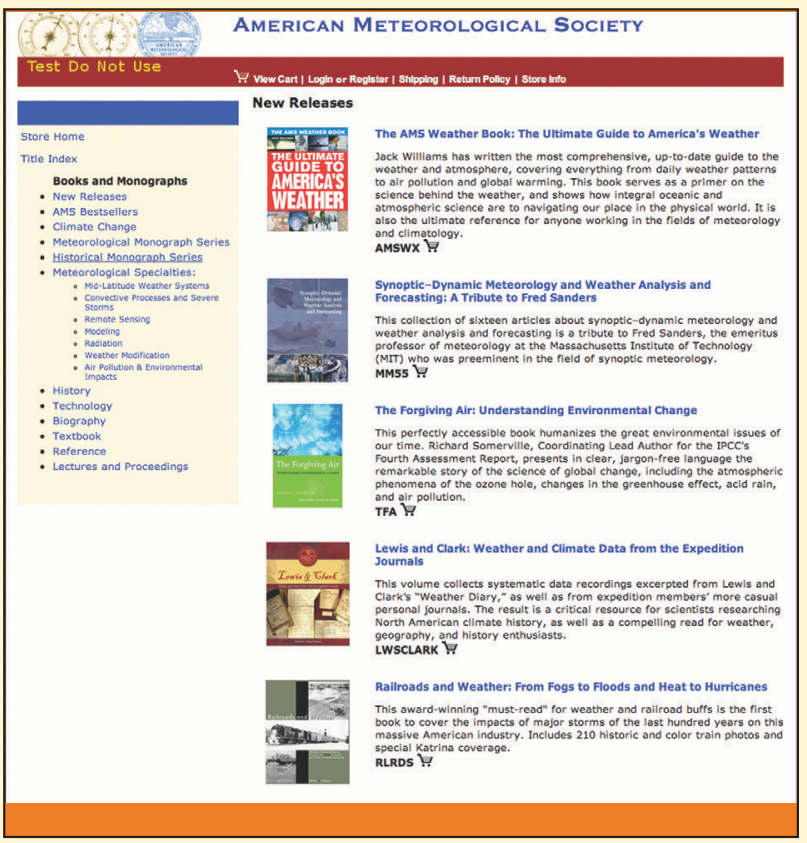

Use this easy-to-navigate site to review and purchase new and classic titles in the collection of AMS Books-including general interest weather books, histories, biographies, and monographsplus much more.

View tables of contents, information about the authors, and independent reviews.

As always, AMS members receive deep discounts on all AMS Books.

\section{www.ametsoc.org/amsbookstore The AMS online bookstore is now open.}

Booksellers and wholesale distributors may set up accounts with our distributor, The University of Chicago Press, by contacting Karen Hyzy at khyzy@press.uchicago.edu, 773-702-7000, or toll-free at 800-621-2736. 